\title{
Circular RNA (circRNA) in Alzheimer's disease (AD)
}

\author{
Walter J. Lukiw* \\ LSU Neuroscience Center and Departments of Neurology and Ophthalmology, Louisiana State University Health Science Center, New Orleans, LA, USA \\ *Correspondence: wlukiw@lsuhsc.edu
}

Edited by:

To-Ha Thai, Beth Deaconess Israel Medical Center, USA

Keywords: micro RNA, miRNA-7, circular RNAs, evolution, gene regulation, Alzheimer's disease, transcriptome, hippocampal CA1

\section{A commentary on}

Circular RNAs are the predominant transcript isoform from hundreds of human genes in diverse cell types

by Salzman, J., Gawad, C., Wang, P. L., Lacayo, N., and Brown, P. O. (2012). PLoS ONE 7:e30733. doi: 10.1371/journal.pone.0030733

Natural RNA circles function as efficient microRNA sponges

by Hansen, T. B., Jensen, T. I., Clausen, B. H., Bramsen, J. B., Finsen, B., Damgaard, C. K., et al. (2013). Nature 495, 384-388. doi: 10.1038/nature11993

Circular RNAs are a large class of animal RNAs with regulatory potency

by Memczak, S., Jens, M., Elefsinioti, A., Torti, F., Krueger, J., Rybak, A., et al. (2013). Nature 495, 333-338. doi: 10.1038/nature11928

Circular RNAs (circRNAs) are a naturally occurring family of noncoding RNAs (ncRNAs) highly represented in the eukaryotic transcriptome. Recently characterized, traditional methods of RNA detection and analysis requiring a free $5^{\prime}$ or $3^{\prime}$ ribonucleotide terminus may have significantly underestimated circRNA abundance and significance in eukaryotic cells (Salzman et al., 2012; Wilusz and Sharp, 2013; unpublished observations). Intrinsically resistant to exonucleolytic RNA decay, circRNAs appear to be enriched in mammalian brain tissues (Hansen et al., 2013; Memczak et al., 2013). Interestingly, specific ncRNAs such as the evolutionary ancient microRNA-7 (miRNA-7; chr 9q21.32; an important post-transcriptional regulator of human brain gene expression), are not only highly abundant in human brain, but are also associated with a circRNA for miRNA-7 (ciRS-7), in the same tissues; ciRS-7 contains multiple, tandem anti-miRNA-7 sequences (Burmistrova et al., 2007; Hansen et al., 2013; Lukiw et al., 2013). ciRS-7 thereby acts as a kind of endogenous, competing, anti-complementary miRNA "sponge" to adsorb, and hence quench, normal miRNA-7 functions. Using Northern blot hybridization techniques and the circularity-sensitive circRNA probe RNaseR we here provide initial evidence of a mis-regulated miRNA-7-circRNA system in the sporadic Alzheimer's disease (AD) hippocampal CA1 region (Figure 1). Deficits in ciRS-7, and ciRS-7 "sponging activities" might be expected to increase ambient miRNA-7 levels in AD-affected brain cells, as is observed, to ultimately contribute to the down-regulation of selective miRNA-7-sensitive messenger RNA (mRNA) targets (Cogswell et al., 2008; unpublished observations). The presence of up-regulated miRNA-7, due to a deficiency in ciRS-7 "sponging" effects, has high probability to down-regulate $\mathrm{AD}$ relevant targets, such as, for example, the ubiquitin protein ligase A (UBE2A; miRNA-7-UBE2A mRNA energy of association, $\left.E_{A}=-22.86 \mathrm{kcal} / \mathrm{mol}\right)$. UBE2A, an autophagic, phagocytic protein essential in the clearance of amyloid peptides in $\mathrm{AD}$ and other progressive inflammatory degenerations of the human CNS, is depleted in AD brain (Bingol and Sheng, 2011; Lonskaya et al., 2013). Such miRNAmRNA regulatory systems mediated by a family of cell- and/or tissue-enriched circRNAs may represent another important

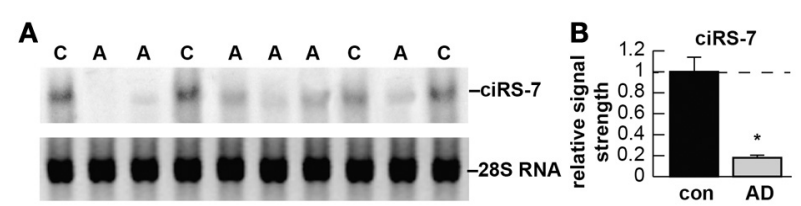

FIGURE 1 | (A) Detection of circRNA for miRNA-7 (ciRS-7) in sporadic Alzheimer's disease (AD) and age-matched control hippocampal CA1 [control (C) $N=4$; AD (A) $N=6$ ]; the single upper ciRS-7 ( $\sim 1400 \mathrm{nt}$ ) band contains $\sim 70$ selectively conserved miRNA-7 binding sites as previously described (Hansen et al., 2013); a lower 28S RNA served as an internal loading control; all samples depleted of rRNA were treated with 50 units of RNaseR prior to electrophoresis RNaseR is a processive, $\mathrm{Mg}++-$ dependent hydrolytic exoribonuclease that degrades linear but not circular RNA; see Hansen et al. (2013); predicted circular transcripts consistently resisted an RNaseR challenge; 30 ug total $A D$ and control hippocampal CA1 RNA was separated on agarose gels, transferred and probed with biotinylated or radiolabeled miRNA-7 probes as previously described (Colangelo et al., 2002: Hansen et al., 2013); detection was performed using a nonisotopic BrightStar BioDetect Kit (Ambion, Austin, TX; detection limit $\sim 100 \mathrm{fg}$ ) or by standard autoradiography (Lukiw et al., 1992); (B) AD ciRS-7 is significantly reduced to about 0.18 -fold of control (con) in a study of 20 control and $A D(A D)$ hippocampal CA1 samples; this implicates loss of miRNA-7 sponge effects, an ambient up-regulation of miRNA-7 (as is observed), and down-regulation of a family of miRNA-7-sensitive mRNAs in the sporadic AD brain; other circRNAs may be involved; there were no significant differences between age for control or AD tissues [mean \pm 1 standard deviation $(S D)=75.4 \pm 8.3$ year vs. $77.5 \pm 7.6$ year]; all $A D$ cases were for moderate-to-advanced stages of $A D$; all post-mortem intervals were $2.1 \mathrm{~h}$ or less (Colangelo et al., 2002); there were no significant differences in age, ApoE allele status, RNA quality (all RIN values were 8.1-9.0) or yield between the control or AD groups ( $p>0.05$, ANOVA); a dashed horizontal line at 1.0 indicates homeostatic (control) ciRS-7 levels for ease of comparison; ${ }^{*} p<0.001$ (ANOVA). 
layer of epigenetic control over gene expression in health and disease. Indeed, technological advancement and recent discoveries in the field of ncRNAs continue to challenge our basic doctrines of nucleic acid biochemistry and evolutionary biology. Deficits in other circRNA-mediated "miRNA sponging systems" and ambient up-regulation of specific inducible miRNAs may help explain the widely observed, generalized and progressive down-regulation of gene expression that is characteristic of the sporadic $\mathrm{AD}$ brain (Loring et al., 2001; Colangelo et al., 2002; Ginsberg et al., 2012; Lukiw, 2013).

\section{ACKNOWLEDGMENTS}

These studies were presented at the Mossakowski Medical Research Centre, Polish Academy of Sciences, in a Symposium entitled "Emerging topics in Neurological disease: molecular mechanisms" held in Warsaw, Poland 24-25 October 2013. Research on miRNA involving signaling, innate-immune responses in $\mathrm{AD}$, amyloidogenesis and neuroinflammation was supported through a COBRE III Pilot Project, a Translational Research Initiative Grant (LSUHSC), NEI EY006311 and NIA AG038834.

\section{REFERENCES}

Bingol, B., and Sheng, M. (2011). Deconstruction for reconstruction: the role of proteolysis in neural plasticity and disease. Neuron 69, 22-32. doi: 10.1016/j.neuron.2010.11.006
Burmistrova, O. A., Goltsov, A. Y., Abramova, L. I., Kaleda, V. G., Orlova, V. A., and Rogaev, E. I. (2007). MicroRNA in schizophrenia: genetic and expression analysis of miR-130b (22q11). Biochemistry (Mosc). 72, 578-582. doi: 10.1134/ S0006297907050161

Cogswell, J. P., Ward, J., Taylor, I. A., Waters, M., Shi, Y., Cannon, B., et al. (2008). Identification of miRNA changes in Alzheimer's disease brain and CSF yields putative biomarkers and insights into disease pathways. J. Alzheimers Dis. 14, 27-41.

Colangelo, V., Schurr, J., Ball, M. J., Pelaez, R. P., Bazan, N. G., and Lukiw, W. J. (2002). Gene expression profiling of 12633 genes in Alzheimer hippocampal CA1: transcription and neurotrophic factor down-regulation and upregulation of apoptotic and pro-inflammatory signaling. J. Neurosci. Res. 70, 462-473. doi: 10.1002/ jnr. 10351

Ginsberg, S. D., Alldred, M. J., and Che, S. (2012). Gene expression levels assessed by CA1 pyramidal neuron and regional hippocampal dissections in Alzheimer's disease. Neurobiol. Dis. 45, 99-107. doi: 10.1016/j.nbd.2011.07.013

Hansen, T. B., Jensen, T. I., Clausen, B. H., Bramsen, J. B., Finsen, B., Damgaard, C. K., et al. (2013). Natural RNA circles function as efficient microRNA sponges. Nature 495, 384-388. doi: 10.1038/nature11993

Lonskaya, I., Shekoyan, A. R., Hebron, M. L., Desforges, N., Algarzae, N. K., and Moussa, C. E. (2013). Diminished parkin solubility and co-localization with intraneuronal amyloid- $\beta$ are associated with autophagic defects in Alzheimer's disease. J. Alzheimers Dis. 33, 231-247. doi: 10.3233/JAD-2012121141.

Loring, J. F., Wen, X., Lee, J. M., Seilhamer, J., and Somogyi, R. (2001). A gene expression profile of Alzheimer's disease. DNA Cell Biol. 20, 683-695. doi: 10.1089/10445490152717541

Lukiw, W. J. (2013). Variability in micro RNA (miRNA) abundance, speciation and complexity amongst different human populations and potential relevance to Alzheimer's disease (AD). Front. Cell Neurosci. 7:133. doi: 10.3389/fncel.2013.00133

Lukiw, W. J., Andreeva, T. V., Grigorenko, A. P., and Rogaev, E. I. (2013). Studying micro RNA function and dysfunction in Alzheimer's disease. Front. Genet. 3:327. doi: 10.3389/fgene.2012.00327

Lukiw, W. J., Handley, P., Wong, L., and McLachlan, D. R. C. (1992). BC200 RNA in normal human neocortex, non-Alzheimer dementia (NAD), and senile dementia of the Alzheimer type (AD). Neurochem. Res. 17, 591-597. doi: 10.1007/BF00 968788

Memczak, S., Jens, M., Elefsinioti, A., Torti, F., Krueger, J., Rybak, A., et al. (2013). Circular RNAs are a large class of animal RNAs with regulatory potency. Nature 495, 333-338. doi: 10.1038/nature 11928

Salzman, J., Gawad, C., Wang, P. L., Lacayo, N., and Brown, P. O. (2012). Circular RNAs are the predominant transcript isoform from hundreds of human genes in diverse cell types. PLoS ONE 7:e30733. doi: 10.1371/journal.pone.0030733

Wilusz, J. E., and Sharp, P. A. (2013). Molecular biology. A circuitous route to noncoding RNA. Science 340, 440-441. doi: 10.1126/science.1238522

Received: 10 December 2013; accepted: 19 December 2013; published online: 31 December 2013.

Citation: Lukiw WJ (2013) Circular RNA (circRNA) in Alzheimer's disease (AD). Front. Genet. 4:307. doi: 10.3389/fgene.2013.00307

This article was submitted to Non-Coding RNA, a section of the journal Frontiers in Genetics.

Copyright (c) 2013 Lukiw. This is an open-access article distributed under the terms of the Creative Commons Attribution License (CC BY). The use, distribution or reproduction in other forums is permitted, provided the original author(s) or licensor are credited and that the original publication in this journal is cited, in accordance with accepted academic practice. No use, distribution or reproduction is permitted which does not comply with these terms. 